Portland State University

PDXScholar

\title{
Vasectomy Disparities among Foreign-Born Latinos Living in the United States : a Preliminary Study
}

Midori Mawi Altamirano

Portland State University

Follow this and additional works at: https://pdxscholar.library.pdx.edu/honorstheses

\section{Let us know how access to this document benefits you.}

\section{Recommended Citation}

Altamirano, Midori Mawi, "Vasectomy Disparities among Foreign-Born Latinos Living in the United States : a Preliminary Study" (2015). University Honors Theses. Paper 296.

https://doi.org/10.15760/honors.212

This Thesis is brought to you for free and open access. It has been accepted for inclusion in University Honors Theses by an authorized administrator of PDXScholar. Please contact us if we can make this document more accessible: pdxscholar@pdx.edu. 
Vasectomy Disparities among Foreign-Born Latinos Living in the United States: A Preliminary Study

by

Midori Mawi Altamirano

An undergraduate honors thesis submitted in partial fulfillment of the requirements for the degree of

Bachelor of Science

in

University Honors

and

Community Health Education

Thesis Adviser

Charles Klein

Portland State University

2015 


\section{Table of Contents}

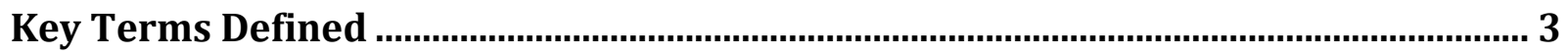

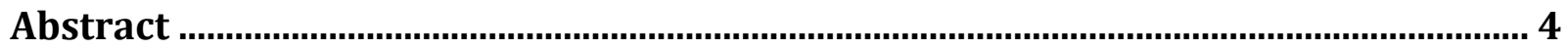

Introduction ............................................................................................................... 5

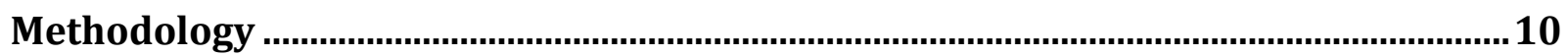

Literature Search Strategy................................................................................................ 10



Vasectomy Disparities among Foreign Born Latinos living in the United States .....12

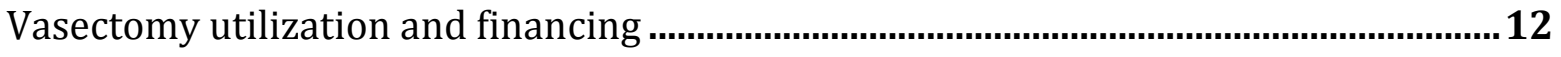

Analysis of Masculinities in Vasectomized Latinos ..................................................... 16

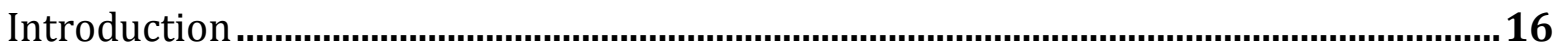

Masculinities and Vasectomy Perspectives among foreign-born Latinos in the U.S.....16

Masculinities and Vasectomy Perspectives in Latin America..........................................21

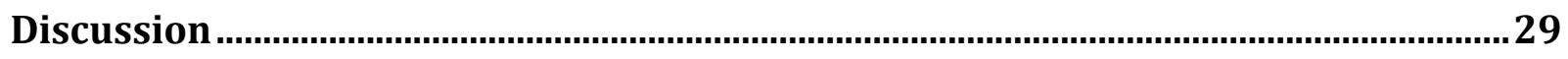






\section{Key Terms Defined}

Latino(s): Men of Latin American/Hispanic origin. In this thesis the word Latino(s) is used instead of Latino man.

Latina(s): Women of Latin American/Hispanic origin. In this thesis the word Latina(s) is used instead of Latino woman.

Foreign-Born Latinos: Based on information from the U.S. Census Bureau, "People who are not U.S. citizens at birth." Foreign-born Latinos differ based on characteristics such as education or nationalities. Therefore, this study uses the category provided by the U.S. Census Bureau but takes into account some of the complex factors that shape the identities of foreign-born Latinos.

Emergent masculinities: “Ongoing, context-specific embodied changes within men's enactments of masculinity, particularly as they encounter emerging health technologies" (Inhorn \& Wentzell, 2011, p. 802).

Hegemonic masculinity: “...pattern of practice (i.e., things done, not just a set of role expectations or an identity) that allowed men's dominance over women to continue...Hegemony [does] not mean violence, although it could be supported by force; it meant ascendancy achieved through culture, institutions, and persuasion" (Connell \& Messerschmidt, 2005, p. 832).

Transnationalism: “... refers to a process through which migrants cross national boundaries and synthesize two societies in a single social field, linking their country of origin with their country of immigration" (Velasco Ortiz, 2005, p.12). 


\begin{abstract}
The number of vasectomized foreign-born Latinos in the U.S. has increased by $2.2 \%$ from 1995-2010 (CDC, 2012). This increase is analyzed using a financial and cultural framework. The study has two objectives: a) examine the accessibility of a vasectomy among foreignborn Latinos, b) explore masculinity traits among foreign-born Latinos that influence their decision to undergo a vasectomy. Based on the literature review, this research study proposes an expansion in vasectomy coverage not only to eliminate health care disparities, but also to decrease expenses in health care costs by providing coverage for a more affordable permanent sterilization method; and the implementation of appropriate public health interventions that take into account the unique masculinity experiences of foreignborn Latinos who are interested in undergoing a vasectomy.

Key words: masculinity, vasectomy, foreign-born Latinos, Latinos, disparities, hegemonic masculinity, emergent masculinity.
\end{abstract}




\section{Introduction}

A common explanation for the high rates of sterilization of women compared to men is that women have historically adopted contraceptive responsibility (Gutmann, 2007). Compared to developing countries, there is a higher prevalence in the number of couples relying on vasectomy in developed countries (Pile \& Barone, 2009). The cause for the higher incidence of vasectomies in developed nations may be related to health care financing, economic circumstances, and cultural background.

In the United States, the recent increased number of vasectomized foreign-born Latinos suggests that the financial and cultural context may play a role in men's decision to undergo the procedure. In order to understand the increase of vasectomized Latinos, it is important to note that some Latin American countries such as Costa Rica, Colombia, Mexico, and Brazil have also reported an increase in the number of vasectomies after the implementation of public health campaigns advocating the procedure (Penteado, 2001, Pomales, 2013, Vernon, 1995). Studies in these Latin American countries indicate that expansion of coverage for the procedure, changes in people's notions of masculinity, and proper public health interventions are some of the factors that are responsible for the increase in the procedure. Taking into account the increase of vasectomies in Latin America, this study examines the health-care financing and cultural context and their possible relationship with the increase of vasectomized foreign-born Latinos in the U.S.

The increase of vasectomies reported in the document Current Contraceptive Use in the United States, 2006-2010, and Changes in Patterns of Use Since 1995 by the CDC (2012) uses the category "foreign-born Latinos" to describe this particular group. For the purpose of this study, the category "foreign-born Latino" is not intended to be applied to all immigrant 
Latinos due to the unique characteristics of each Latino community. This can be observed in the complex relationship Latinos from Puerto Rico have with the U.S. ranging from particular bills that regulate health care access to immigration benefits gained from being part of a U.S. territory. As a result, Puerto Ricans' access to vasectomies and exposure to foreign masculinities may differ from Latinos from other countries such as Guatemala or Mexico. Therefore, it is important not to generalize the information in this study, as foreignborn Latino characteristics vary greatly depending on diverse factors such as country of origin, education, socioeconomic status, and immigration. By focusing on commonalities, such as access to health care resources and masculinity characteristics among foreign-born Latinos, this study seeks to identify possible causes for the increase of vasectomies among this population.

In the U.S., foreign-born Latinos are more likely to suffer from health care disparities as a result of their language, socioeconomic status, and cultural barriers. In addition, lack of proper documentation is a barrier to obtaining health insurance in the exchange programs supported by the Affordable Care Act. The Pew Research center reported that about half of foreign-born Latinos lacked health insurance in 2012; moreover, $61 \%$ of those who were non-citizens had no health insurance (Krogstad \& Lopez, 2014). Consequently, a significant number of foreign-born Latinos face financial barrier in accessing contraceptive methods or permanent sterilization procedures in the U.S.

Even though some states are providing more extensive coverage for female sterilization through the Medicaid expansion, coverage is not widely available at the same rate for male sterilization (Ranji, Salganicoff, Stewart, Cox, Doamekpor, 2009). Not providing equal coverage for both sterilization procedures increases the disparities in 
access to reproductive health (Nguyen, Shih, \& Turok, 2014). Thus, multiple social categories—such as gender and/or immigration status—could result in the unequal coverage of sterilization procedures and contribute to health disparities among foreignborn Latinos living in the U.S. Nonetheless, despite the inequality in vasectomy coverage, an increase of $2.2 \%$ in the number of vasectomized foreign-born Latinos has been observed in the last 15 years (CDC, 2012). This study acknowledges the limitations of using the CDC 2012 report since it is based on interviews with women aged 15-44 between 1995 and 2010 and did not include male subjects. In addition, detailed information explaining whether the vasectomized foreign-born Latinos had the procedure done in the U.S. or abroad is not present in the CDC report. Considering there is no nationwide vasectomy incidence or prevalence report in the U.S. (Pile \& Barone, 2009), the CDC 2012 report on contraceptive use is one of the few documents providing the most current vasectomy utilization information among foreign-born Latinos in the U.S.

To complement the findings of the CDC's 2012 contraceptive use report, this study draws on research conducted in Latin American countries where there has been an increase in vasectomy utilization. The studies in Latin America have not only focused on the promotion of the procedure through public health interventions, but also on the possible relation between changes in masculinity traits and acceptance of vasectomy procedures (Penteado et al., 2001; Pomales, 2013). Considering the commonalities between Latinos in their home countries and the U.S., it is hypothesized that a combination of factors—such as affordability/accessibility and changes in masculine identities-may have influenced immigrant foreign-born Latinos in the U.S. to have more acceptance of the procedure and consider a vasectomy as an option of permanent sterilization. 
Men in Latin America have until recently not undergone vasectomies because of the belief that removing a men's capability to procreate will result in the loss of hegemonic masculinity traits, such as virility and procreation (Gutmann, 2004). However, academic research in four Latin American countries has documented an increase in the number of vasectomies performed and theorized the factors that influence Latino men to undergo the procedure. The studies suggest that vasectomies challenge social constructs of hegemonic masculinity in Latinos by allowing men to care for their families and be more engaged with contraceptive responsibility (Penteado et al., 2001; Pomales, 2013; Vernon, 1996). As stated by Pomales (2013), vasectomies facilitate the development of emergent masculinities as men embody new characteristics that oppose some of the characteristics of the hegemonic "macho". At the same time vasectomy is a means to support emergent masculinities by providing the opportunity for men in Latin America to redefine their household size, traditional gender roles, and adopt contraceptive responsibility as part of the male role.

The development of diverse masculinities and acceptance of a vasectomy as a method of sterilization is also observed in immigrant Latinos in the U.S. whose transnational identities question the characteristics of the hegemonic "macho" (Vasquez-Aguila, 2014; Lu \& Wong, 2014). For example, many of the foreign-born Latinos living in the U.S. come from rural areas where they are influenced—but not necessarily defined—by ideas of the stereotypical "macho" behavior, but then experience different and competing constructions of masculinity in the U.S. In many rural areas of Latin America, a large family size is both a demonstration of male virility and an economic strategy to supply the manual labor needed to work the land. In this context, the idea of male sterilization works against both gender 
norms and prosperity. However, upon arrival in the U.S., many Latinos encounter a different social/economic system where a large family size may actually hinder a Latino's opportunity to succeed due to the limited resources available. In addition, for many foreign-born Latinos, economic prosperity is difficult to achieve due to the lack of family support for childcare, not knowing the language, or not meeting some of the requirements needed (such as education or immigrant documentation) for a well-paying job. These factors may impede foreign-born Latinos from developing their role as the provider and obtaining the opportunity to economically support a large household. Latinos' limited economic opportunity coexists with the increased economic independence of foreign-born Latinas in the U.S., which further challenges the provider role of the hegemonic "macho" (Torres, 1998; Weis, Centrie, Valentin-Juarbe, \& Fine, 2002).

Having a large family size and following traditional gender roles do not necessarily provide foreign-born Latinos the best strategies to prosper in a new environment. A small family size may be more desirable and provides a possible explanation for the increase of vasectomized foreign-born Latinos. Even though it is not clear if these men decided to undergo the procedure in their home countries or in the U.S., this literature research notes that the shifting masculinities occurring among Latinos in the U.S. and in their countries of origin are crucial to understanding the acceptance of vasectomies among foreign-born Latinos. Thus, the increase of vasectomized foreign-born Latinos could be explained by examining how health care systems and cultural factors support men's decision to undergo a vasectomy and be more involved in contraceptive matters. 


\section{Methodology}

\section{Literature Search Strategy}

This literature review focused on peer reviewed articles, governmental reports and policy analyses. The peer-reviewed articles were accessed using the Portland State University and the Columbia University Library System. The main databases used in this literature review were SAGE and JSTOR. Documents from different fields of study were used in this literature review in order to provide a comprehensive view: Public Health, Sociology, Anthropology, Economics, and Medicine. Scholarly books, governmental publications, and reports from foundations and non-profits were accessed using Google Scholar as a secondary searching tool. With the exception of three sources, the data collected ranges from 2001 to 2015. In order to expand the data collected for this literature research, some of the keywords were translated into Spanish. Key search words included a combination of the following terms: vasectomy, foreign-born Latinos, immigrants, masculinity, Latinos, Hispanic, male sterilization, ACA, Obamacare, gender roles, hegemonic masculinity, emergent masculinities, intersectionality, transnationalism, machismo, male reproductive health care, and contraceptive responsibility. All documents were organized using Zotero, and electronic and paper copies of the documents were kept.

\section{Study Selection Criteria}

To be selected for review, articles had to meet the following criteria: (i) peer-reviewed journal articles, government data, or reports from foundations; (ii) published in English or Spanish between January 2000 and March 2014 (with the exception of three studies).; and (iii) the information included data on vasectomies or masculinity. Given the extremely 
limited research on vasectomies among foreign-born Latinos in the U.S., I expanded my search to include research related to (1) vasectomies, sexual health, and masculinities among Latinos in Latin American countries, and (2) reproductive and sexual health among Latinas and Latinos in the U.S., regardless of where they were born. 


\section{Vasectomy Disparities among Foreign-Born Latinos living in the U.S.}

\section{Vasectomy utilization and financing}

In the United States, the cost of permanent sterilization procedures varies according to health insurance coverage. Based on information collected from Planned Parenthood Federation of America, vasectomies can cost up to $\$ 1,000$ and tubal ligations can cost $\$ 6,000$ or more (Planned Parenthood, 2014). There are also differential health risks and costs associated with the procedures themselves. The cost of tubal ligations is higher because it includes charges for hospitalization and anesthesia. Vasectomies, on the other hand, only require local anesthesia and are a less risky, ambulatory procedure. Furthermore, the cost of a tubal ligation can increase because the risks associated with the procedure are 20 times higher than those of a vasectomy (Nguyen et al., 2014). The consequences of failed vasectomies versus failed tubal sterilizations vary greatly as well. Failed vasectomies can lead to intrauterine pregnancies, which in case of termination, carry a minimal risk and cost approximately $\$ 600$. If the patient decides to continue with the pregnancy, delivery charges are about $\$ 9,318$. However, a failed tubal ligation has a 33\% risk of ectopic pregnancy, which can cost around $\$ 10,613$ to be treated. Besides the costly treatment, ectopic pregnancies carry a high risk of morbidity and mortality (Nguyen et al., 2014). Therefore, the costs and risk associated with vasectomies are less severe than those of tubal ligation (Eisenberg, 2009; Nguyen et al., 2014; Shih, Dubé, Sheinbein, Borrero, \& Dehlendorf, 2013). Despite the relative advantages of vasectomy procedures, health care insurances nonetheless cover tubal ligations at a higher rate compared to vasectomies.

The Patient Protection and Affordable Care Act (ACA) support the coverage of contraceptives and sterilization for women under the Health Insurance Marketplace. 
However, despite the lower costs and health risks associated with vasectomies compared to female sterilization, the ACA does not require insurance to provide coverage for male sterilization (Nguyen et al., 2014). In this manner, the ACA policies provide more extensive coverage for the most expensive sterilization procedure over the much more affordable vasectomy option.

Eisenberg's study of sterilization in the U.S. indicates that in 2009, female sterilization was over two and a half times more common than vasectomies with a rate of $16 \%$ versus $6 \%$ (Eisenberg, 2009). This data suggests that health disparities in access to permanent sterilization may be caused by the unequal coverage to the procedure based on the sex of the patient. The opportunities for men to take contraceptive responsibility are likely hindered by restrictive male sterilization policies. In addition, the exclusive coverage of female sterilization under the ACA may contribute to an environment of stigma in men's role in reproductive health. This may additionally cause negative health outcomes in men who will likely have fewer opportunities for routine check-ups and STI testing.

Due to the limited ACA coverage in the Insurance Marketplace for vasectomies, individuals with a more comprehensive insurance coverage or those who are able to pay for services out-of-pocket have the privilege to choose their preferred method of sterilization. For example, insured women with incomes of $150 \%$ over the poverty level reported that their partners chose a vasectomy as a permanent method of sterilization at a higher rate than other women (CDC, 2012). Nevertheless, individuals with restricted health care coverage have limited options for contraceptive care as explained by the Summary Survey from the Kaiser Family Foundation (Ranji et al., 2009). According to the Summary, Medicaid recipients can receive coverage for vasectomies and tubal ligations in 37 states. 
Furthermore, some states have expanded coverage using the Medicaid Waiver Program for people unable to qualify due to state-set income eligibility or not meeting categorical requirements, such as citizenship. Each state has the ability to decide the specific requirements to qualify under the Medicaid Waiver Program and what procedures to cover. Under the Medicaid Waiver Program, 13 states cover tubal ligation post-partum and 20 states cover it after another procedure. In contrast, vasectomy coverage under the Medicaid Waiver is limited to 10 states.

Those who are unable to qualify for the Insurance Marketplace or Medicaid, live in states where Medicaid does not cover vasectomies, or cannot afford the procedure out-ofpocket, have less or no options available to cover the expenses of sterilization procedures. Foreign-born Latinos are one of the groups who are directly affected by the disproportionate coverage of the procedure since, on many occasions, immigration and socioeconomic status becomes a barrier to qualify for male sterilization coverage. It is possible that high rates of female sterilization and significantly low rates of vasectomies observed in foreign-born Latinos are caused by disparities in access to vasectomies. According to CDC (2012), data collected between 2006 and 2010, the percentage of foreign-born Latinos who used female sterilization (36.5\%) was higher than the percentage of white women who undergo the procedure (23.6\%). In addition, the percentage of sterilization in white males (13.3\%) is more than double the percentage of foreign-born Latinos (6.0\%) who had the procedure. In terms of trends, the percentage of vasectomies in white men has remained steady from 1995-2010. Nonetheless, there has been a slight increase of $2.2 \%$ in vasectomized foreign-born Latinos during the same time period. This study examines two possible causes for this increase: a) masculinities of foreign-born 
Latinos are being affected by the emergent transnational identity that promotes an egalitarian household and the use of vasectomies, and b) access to vasectomy coverage and public health programs in Latin American countries supports the decision of these men to undergo the procedure. 


\section{Analysis of Masculinities in Vasectomized Latinos}

\section{Introduction}

Gender hierarchy theories propose that a common characteristic of gender roles across space and time is the subordination of women under men (Ortner, 1989; Reiter, 1975). Feminist anthropologist Rayna Reiter argues that the earliest societies were egalitarian, but male dominance began to develop with the roles of male-hunter and female-mothering, arranged marriages (where women were exchanged for goods), and the introduction of colonialism and a class based society (1975). Reiter indicates that social systems have historically supported gender hegemonic power as a characteristic primarily intrinsic to men. To account for this imbalance, Connell proposes the concept of "hegemonic masculinity" to define the normative of men's dominance over women in society (2005). Some of the characteristics linked to hegemonic masculinity are "social dominance, including command of wealth and resources, attractiveness, virility, physical strength, heterosexuality, and emotional detachment" (Inhorn \& Wentzell, 2011, p. 802). Consequently, the hegemonic masculinity characteristics presented by Inhorn and Wentzell are present in the characteristics of the stereotypical "macho", an archetype which traditionally_but not solely_defines the way to be a man in Latino culture. Sexuality and contraceptive responsibility norms are well defined for the "macho", whose ideas of reproductive health, family size, and unwillingness to have a vasectomy are reinforced by traditional hegemonic traits.

\section{Masculinities and Vasectomy Perspectives among foreign-born Latinos in the U.S.}

Foreign-born Latinos come to the United States seeking better opportunities not available in their home countries. Upon arrival into the U.S., immigrants realize that they 
have higher chances of achieving progress if they adapt to established norms in the U.S. (Vasquez del Aguila, 2014). The U.S. exposes foreign-born Latinos to diverse sexual and reproductive representations that many times differ from traditional ideas of family size, gender roles, birth control utilization, and masculinity (Maternowska, Withers, \& Brindis, 2014). In Latin America, for example, hegemonic masculinity traits support the role of male authority, but in the U.S. male authority may be questioned since this society is considered to be more egalitarian (Donaldson, Hibbins, Howson, 2009; Maternowska et al., 2014; Torres, 1998; Weis et al., 2002). According to Hondagelu-Sotelo, “...Mexican male immigrants in the United States found that their patriarchal privileges were significantly diminished in the process of migration" (Donaldson et al., 2009, p. 80). In consequence, foreign-born Latinos develop emergent masculinities due to the need to adapt to a new society and develop strategies to withstand the decline of their authority (Vasquez del Aguila, 2014).

In the United States, immigrant men's contribution to the family economy may be lower due to unemployment and low paying jobs while many immigrant women are able to achieve economic power allowing them to be more independent (Donaldson et al., 2009; Lu \&Wong, 2014; Torres, 1998). As a result, gender relations have the potential to be renegotiated in the new territory. These dynamics could be experienced as a form of emasculation for foreign-born Latinos who live under the stress of not performing the typical role of the provider, based on hegemonic masculinity (Torres, 1998). However, these shifts in household economics also create the opportunity for the development of new masculinities that will adopt an egalitarian household and offer women the opportunity to be providers. 
The adaptation into a new society challenges men's traditional ideas of gender roles. Weiss' study of masculinity changes—including patriarchal authority—in Puerto Rican men, highlights how Latino men in the U.S. are often unable to reclaim obedience from women. The role of the provider is lost because women have now claimed that role. As one man explains:

... the man feels that a woman doesn't have the right to question him... which is fine and dandy, because in the old times the men earned that right, to head the household. He worked, supported the family... And now they [men] want the same respect, without having to work for it. And it just cannot happen. (Weis et al., 2002, p. 299)

Another example can be observed in an interview with a Mexican field worker about the changes in gender roles upon arrival into the U.S.:

You have to respect them [women] more because now they have almost the same rights as a man and the same opportunities to get ahead and to succeed, and women are supported more here [U.S.]. That has changed. Before, everything revolved around the man, and the woman stayed at home, [and] was submissive, waiting for her husband to get home from work. But not now. (Maternowska et al., 2014, p. 995)

For these Latino immigrants, the provider role gave them a sense of entitlement to subordinate women. However, the current society in which these immigrants live does not allow them to demand obedience for women because the role of the provider does not uniquely belong to men. 
Losing the provider role could cause anxiety in foreign-born Latinos since it may emasculate their identity. For some men, not being the provider-due to the difficulty of finding employment or having a low-wage job-creates depression and feelings of guilt for not enacting their traditional hegemonic male role (Torres, 1998). For others, this becomes an opportunity to challenge hegemonic masculinity identities and accept diverse representations in gender roles. As an immigrant Mexican man stated, "I had to adapt into the society and the way people here see women as a participating member of society, because it's important to them" (Donaldson et al., 2009, p. 91).

Changes in masculinity identities may benefit some foreign-born Latino immigrants since they will be less likely to be victims of prejudice or discrimination by adapting to the egalitarian gender roles of the new society (Lu \& Wong, 2014). In addition, the adoption of emergent masculinity characteristics may also alleviate anxiety among foreign-born Latinos who feel constricted by rigid gender roles. While contraceptive responsibility has historically been part of the woman's gender role, in an egalitarian household contraceptive use is a shared responsibility among a couple. In this manner, the characteristics of this emergent masculinity that supports the development of an egalitarian household contrasts with traditional hegemonic masculinity traits which associate vasectomies with emasculation. Exposure to diverse masculinities combined with the new challenges involved with migration may support the use of vasectomies among the foreign-born Latino community. The male role of the provider may also be easier to achieve with a smaller family size given the limited resources available to many foreign-born Latinos (Sable, Campbell, Schwarz, Brandt, \& Dannerbeck, 2006). In this manner, traditional normative gender roles may be dismantled amid the new challenges and 
opportunities that become available in a new territory. While in the past it was customary for women to have contraceptive responsibility, now both female and male sterilization are considered as options to limit the household size and provide an opportunity to achieve progress in the foreign land.

As it was previously stated, the number of vasectomized foreign-born Latinos has increased in the United States. A qualitative study done by Shih on the decision to undergo a vasectomy among a racially diverse population provided some responses from Latinos living in the U.S. An interviewed Latino stated, "There are many advantages for me. To be able to raise one child better, give them better schooling, better attention" (Shih et al., 2013, p. 209). Investing in the future of the family is important for foreign-born Latinos because with a small family size Latinos are able to provide more resources to their children. As a matter of fact, the importance of family investment is confirmed in Lu's study of masculinity among U.S. born and immigrant Latinos. The findings suggest that it is important for immigrant Latinos to invest in the family as this could be an opportunity for their children to overcome the disadvantages that they, their immigrant parents, had to go through (Lu \& Wong, 2014). This statement is illustrated in an interview with a Latino immigrant who stated that, "Your children have to pay for not planning your family. Instead of going to school, they exchange a pencil for a plough" (Sable et al., 2006, p. 391). In this context, vasectomies could be used as a tool to increase the opportunity to provide family members with more resources and overcome generational disadvantages.

The qualitative study done by Shih also found that for some Latinos the decision to undergo a vasectomy is linked to characteristics of having an egalitarian household where men and women share responsibilities, including contraceptive responsibility. In the study, 
a Latino stated that, "[Vasectomy is] the best option because of my wife... she got two babies and one surgery and now it is my time" (Shih et al., 2013, p. 209). Contraceptive responsibility in this case is seen as a shared responsibility where men are willing to undergo the procedure to demonstrate that both partners have equal roles in taking care of the household. The studies suggest that vasectomy procedures signify more than just a method of sterilization for Latinos. Vasectomies provide Latinos the opportunity to recover their provider role by giving them control over the household size, while preserving more resources for the family. In addition, vasectomies change traditional Latino family dynamics by promoting an egalitarian household. As it can be observed, vasectomies could be used as a strategy for foreign-born Latinos, who develop a transnational identity as a result of the unique financial and cultural circumstances experienced in the foreign land.

While we cannot generalize from the statements made in Shih, Sable, and Lu's studies, they suggest that vasectomized foreign-born Latinos in the United States may be influenced by new concepts of masculinity. It is important to note that other factors such as education, religion, or socioeconomic status may influence these men in their decision as well. Since the CDC 2012 report on current contraceptive use does not specify if the vasectomized Latinos had the procedure performed in the U.S. or abroad, it is important to consider how both public health programs in Latin American countries and transnational Latino masculinities could play a role in the increase of vasectomized foreign-born Latinos in the U.S.

\section{Masculinities and Vasectomy Perspectives in Latin America}

Hegemonic masculinity has been reinforced throughout the history of Latin American culture, where colonial and postcolonial traditions have strongly defined gender 
roles empowering men and disempowering women (Connell, 2014). For example, many Catholic traditions brought to Latin America during colonial times are ingrained in Latin American culture and reinforce traditional gender roles such as "machismo" and "marianismo" which reinforces the dominance of men over submissive women (FernandezEsquer, Diamond, \& Atkinson, 2010). In addition, the proliferation of other religious denominations in Latin America, such as the Evangelical Protestants, Mormons, and the Jehovah's Witnesses, intensifies the gender dynamics that reinforce the characteristics of the hegemonic macho. The gender dichotomies are also present in Latino media and other popular venues where Latinos are many times portrayed with the characteristics of the hegemonic macho such as “... womanizer, dominant, sexist, jealous, and violent” (Martínez Hernández, 2012, p. 128, own translation¹). Montoya analyzes the Nicaraguan expression “El hombre hace valer a la mujer' (men give women value) as an example of the dynamics of traditional gender dichotomies taking place in Latin America. According to Montoya, the expression suggests that "in return for protection, respect, and economic stability, the wife was to uphold the respectability of the house by keeping to a set of clearly prescribed practices" (Montoya, Frazier, \& Hurtig, 2002, p. 70).

A weakness in defining gender hierarchies based on rigid dichotomies of machismo and marianismo is that it overgeneralizes the complex and diverse dynamics that take place in Latino societies. June Nash explains that gender dynamics are in constant evolution based on the "historical and cultural specificity of local practices and meanings" (Montoya et al., 2002, p.289). Women in Latin America-as in other parts of the world-are increasingly taking part in the workforce, which many times results in an increased

\footnotetext{
${ }^{1}$ Original quote: “... mujeriego, dominante, sexista, celoso y golpeador” (Martínez Hernández, 2012, p. 128).
} 
pressure on men's traditional gender roles (Connell, 2014). For example, the emergence of a new form of masculinity is illustrated in the case of a Latino business man who described how he had to adjust his "macho" behaviors once his wife earned more money than he did (Carrera \& Meráz, 2010). Similarly, anthropologist June Nash explains that women in Latino societies are increasingly displaying hegemonic femininity power resulting from “'transgressions' of women in places dominated by men” (Montoya et al., 2002, p. 293).

The coexistence of different forms of masculinity in Latin America represents an opportunity for traditional gender roles—such as contraceptive responsibility—to be redefined. Gutmann (2004) suggests that traditions in Latin America support the low levels of participation of men in family planning. This statement may explain the low number of vasectomies in Latin America compared to the U.S.-1.9 million versus 4.2 million, respectively (Pile \& Barone, 2009). Despite the low prevalence of vasectomies in Latin America, public health interventions promoting vasectomy in regions of Brazil, Costa Rica, Mexico, and Colombia have shown to increase vasectomy utilizations. It is observed that traditional masculinity traits are not adopted by all Latin American men because gender hegemony varies according to place; thus, promoting the development of diverse gender dynamics (Montoya et al., 2002). Therefore, it is possible that in Latin America the presence of hegemonic and emergent masculinities influence men's perspectives on reproductive health and vasectomy utilization.

The prevalence of hegemonic masculinity traits in many Latino societies that connect male fertility, virility, and masculinity - the defining characteristics of the stereotypical macho-may be a cause for the lower rates of vasectomy (Pomales, 2013). In an ethnographic study by Gutmann (2004) in Oaxaca, Mexico, men did not consider 
vasectomy as a method for sterilization because they were afraid either that the procedure would result in their inability to have intercourse and/or becoming homosexual. The fear of becoming homosexual is discussed during interviews to men in Oaxaca where Gutmann states that "... the half-joking banter devolved to a related sexual anxiety, the worry that a man might "be turned" as a result of the procedure (vasectomy) — that is, that he might come out of it wanting to have sex only with other men" (2007, p. 160).

Men in rural areas are not the only ones expressing fears about vasectomies and loss of masculinity. In Pomales's ethnographic study in San José, Costa Rica one vasectomized man, when referring to the reason for men not to get operated, explained, "man had a tendency to think that if he got operated [had a vasectomy] he would lose his virility, and that he wouldn't be able to get erections, and that he wouldn't be able to have sexual relations. And so, the men never thought of getting operated" (Pomales, 2013, p. 24-25). In Latin America, one of the reasons vasectomy misconceptions are prevalent is due to the lack of accurate information disseminated about the procedures (Gutmann, 2004). Nonetheless, some countries in Latin America, such as Brazil, Colombia, Costa Rica, and Mexico, have used strategies to promote the procedure, resulting in the increase of vasectomized men in the places where the programs took place.

It is important to note that health care institutions frequently promote hegemonic masculinities, as "... doctors and nurses reveal their own prejudices and preferences for women to assume this [contraceptive] obligation" (Gutmann, 2007, p. 142). The systemic gender biases are noted by Vernon (1996) who states that for a successful vasectomy program, health care personnel should be appropriately trained to counsel and promote the procedure. In addition, the successful implementation of health care programs that 
promote vasectomies in Brazil, Colombia and Mexico suggest that there is a demand for vasectomy procedures in these countries; however, the lack of institutional resources available to supply the demand for vasectomies may have resulted in the low prevalence of the procedure. (Vernon, 1996; Penteado et al., 2001). When changes at an institutional level meet the demand for male sterilization, as seen in Costa Rica, it results in an increased number of vasectomies, which coincides with a decreased number of tubal ligation (Pomales, 2013). These studies suggest that when institutional changes-such as training of providers and increasing access for the procedure-are properly implemented many men are eager to be involved in taking contraceptive responsibility.

Providing information and access increases the prevalence of vasectomy procedures, which are in turn interconnected with the transformations in the masculinity traits of Latinos. As explained by Inhorn and Wentzell (2011), “emergent masculinities codevelop with changes in the ideas and possibilities for men's physical embodiment across the life course and at different times and places" (p. 803). While in the past the "macho" behavior was widely accepted in Latin American culture, some vasectomized Latinos question the characteristics of the "macho". Embodying a new type of masculinity, vasectomized Latinos find the traditional macho as a symbol of backwardness and use their vasectomy as a symbol of achieving progress (Pomales, 2013; Penteado et al., 2001; Gutmann, 2004). As stated by a vasectomized Costa Rican man, If you would have said that (having a vasectomy) to my grandfather he would have shot you. Because of his machismo... But not us. We are already a new generation. A generation that thinks, analyzes things, and sees things much more clearly. (Pomales, 2013, p. 25) 
By adopting a modern identity, some vasectomized Latinos express their desire to be separated from the traditional "macho". The tendency to reject the macho and the characteristics of hegemonic masculinity entails the rejection of some traditions-such as men having power over the household and being the only decision makers—of Latin American cultures (Carrera \& Meráz, 2010).

A man who embody non-traditional masculinity traits also consider care for their family and love for his wife as reasons to undergo a vasectomy procedure. As explained by a man in Costa Rica:

... I believe I wouldn't want to give a child to any other woman. If with my wife I have one child, and I feel very happy with her, very satisfied, and [if] I'm not going to have another one with her, then with nobody else. (Pomales, 2013, p. 23)

The sterilization of this man not only results in permanent changes to his reproductive organs, but also in a permanent demonstration of love for his wife. This also illustrates the characteristics of an egalitarian household where men and women share equal responsibilities, including contraceptive responsibility. Men displaying this behavior have been described as portraying a mature masculinity under which “... male faculties are used in benefit of the partner, creating relationships free of social prejudice, and where feelings are expressed freely" (Carrera \& Meráz, 2010, p. 9, own translation²).

Vasectomy procedures may promote the emergence of new masculinities in Latinos, but they can also reinforce the hegemonic masculinity and the traditional power of men over women. In Gutmann's Oaxaca study, a woman whose husband had a vasectomy

\footnotetext{
${ }^{2}$ Original quote: “... la masculinidad madura, la cual permite hacer las facultades masculinas en beneficio de la pareja, se generan relaciones más libres de los prejuicios sociales, y se expresan libremente los sentimientos" (Carrera \& Meráz, 2010, p. 9).
} 
explained that her partners' vasectomy is a way to protect his marriage from "outside" pregnancies and the ensuing financial and emotional obligations. Other men in the interviews expressed that their vasectomies will allow them to control their wives because they will know if the wife got pregnant from having sex with another man (Gutmann, 2007). Both of these affirmations about vasectomies in Latinos reinforce characteristics of the hegemonic macho, such as being proud of his womanizer capabilities and showing dominance over women - referring to them as personal possessions.

The coexistence of hegemonic and emergent masculinities is part of the unique blend of tradition and modernity influencing Latin American societies. Men with diverse representations of masculinities who undergo the procedure react differently to sharing with their community about their decision to undergo a vasectomy. Some men prefer to hide the fact that they had a vasectomy to their community (Gutmann, 2007), while others are proud and have no issues about sharing their vasectomy experience. Similarly, a Brazilian man describes:

Do you know what is said to me, 'Ah, you had a [vasectomy], you must be weak.' I said, 'I will get your wife' (laughter). 'Get your wife and bring her to my wife and then they can both talk together in front of us. Ask who has more sexual potency, is it me or you? Send your wife to talk with mine, and mine can tell yours. I want to see which one of us is going to laugh in the other's face. (Penteado et al., 2001, p. 324) Besides displaying sexist comments-which is another trait entrenched in the stereotypical macho-this man is publicly breaking the stereotype that surrounds vasectomy procedures, such as loss of male sexual potency or homosexuality. The way in which this man communicates his vasectomy experience makes him appear proud and confident of his 
masculinity. These characteristics correlate with the fact that many vasectomized men act as opinion leaders who support male contraceptive responsibility (Penteado et al., 2001; Pomales, 2013). Considering that friends and family are very influential in the decision of Latino men to undergo the procedure, vasectomized men encourage vasectomy procedures in the community and are the main contributors in the increased number of vasectomiesas seen in Brazil, Colombia, and Mexico (Vernon, 1996).

Vasectomy procedures have put into question some of the characteristics of the hegemonic macho. However, it appears that masculine identities in Latin America are in a process of transformation represented by men adopting vasectomy as a method of family planning. As explained by Ortner (1989), "Hegemonies are powerful, and our first job is to understand how they work. But hegemonies are not eternal. There will always be (for both better and worse) arenas of power and authority that lie outside the hegemony and that may serve as both images of and points of leverage for alternative arrangements" (p. 80). As long as the traditional macho figure was the dominant figure in Latin America, the idea of vasectomies as a method of family planning for Latinos was unacceptable. Nowadays, the diversity of masculine identities in Latin America provide the opportunity for men with different masculinity characteristics—from hegemonic to emergent—-to consider vasectomies as a method of birth control when adapting to the needs of a different society. 


\section{Discussion}

Despite the health care disparities affecting Latinos in the U.S., data from the CDC indicates that there has been an increase in vasectomized foreign-born Latinos. The growth of vasectomized foreign-born Latinos may be attributed to either an increase in vasectomies performed in the U.S. among foreign-born Latinos or the immigration of vasectomized Latinos into the U.S., or both. This study observed that many foreign-born Latinos in the U.S. are unable to access or afford a vasectomy due to immigration status and cost of the procedure. Data from Latin American countries indicate that both accessibility and affordability are some of the factors that influence Latinos in their decision to undergo a vasectomy. Studies in the U.S. and Latin America also suggest that financing is not the only factor influencing a Latino's decision to undergo the procedure.

After reviewing data related to masculinity on vasectomized foreign-born Latinos in the U.S. and their home countries, it was evident that these men shared several common reasons for undergoing the procedure such as, caring for their wife, promoting a shared contraceptive responsibility role, and providing a better future for the family. Studies on masculinities in Latin America indicate a possible correlation between Latinos' perspectives on vasectomies and the adoption of emergent masculinity identities. In addition, studies in the United States indicate that masculinity identities in immigrants are influenced by the unique barriers they face in the foreign country. Despite the geographical difference, it is observed that common emergent masculinity characteristics among vasectomized Latinos in the U.S. and Latin American countries are present. Vasectomized Latinos in Latin America and the U.S. emphasize that the role of the provider is important and that their vasectomies allowed them to achieve this role by allocating more resources 
for the family. Another commonality found is that vasectomy utilization appears to increase among Latinos as egalitarian households develop. While the findings in this literature review should not be generalized to all Latino communities, it is important to understand emergent masculinities in foreign-born Latinos and the influence they have on vasectomy utilization. Research methods with a collaborative community approach-such as community based participatory research—are recommended to develop vasectomy campaigns tailored to the characteristics of a specific Latino community.

The intersection of health care systems and cultural factors may provide an explanation of the increase of vasectomized foreign-born Latinos in the U.S. Given the lack of coverage for vasectomy procedures in the U.S., the increase of vasectomized Latinos may be a result of the implementation of affordable services and culturally appropriate public health programs in Latin American countries. In addition, the increased popularity of vasectomies among foreign-born Latinos may be due to changes in masculinity traits, both in the U.S. and in Latin America, promoting the acceptance of shared contraceptive responsibility and a small family size. If expansion of vasectomy coverage is implemented in the U.S. and public health interventions that take into account masculinity experiences of foreign-born Latinos are implemented, we may see a continued increase in vasectomized Latinos in the years to come. In addition, the expansion of vasectomy coverage could also decrease health care expenses in the U.S. since vasectomies are a more affordable method of permanent sterilization.

The purpose of this study is not to massively target foreign-born Latinos to have a vasectomy, but to provide them the resources and information needed to enable them to make the best decisions for themselves and their families. Everyone should have the right 
to employ reproductive autonomy in their family size decision. This autonomy should not be hindered by elements such as gender, SES, insurance, or immigration status. Despite the limitations of this study, it is undeniable that health care disparities are present in the United States, making foreign-born Latinos less capable of having reproductive choices regarding family size. 


\section{Bibliography}

Carrera, R. M., \& Meráz, R. C. (2010). Cambio Cultural y Masculinidades Emergentes. Fazendo Gênero, (9). Retrieved from:

http://www.fazendogenero.ufsc.br/9/resources/anais/1277227142_ARQUIVO_Ma sculinidadesBRASIL.pdf

Centers for Disease Control and Prevention (CDC). (2012). Current Contraceptive Use in the United States, 2006-2010, and Changes in Patterns of Use Since 1995. Retrieved from http://www.cdc.gov/nchs/data/nhsr/nhsr060.pdf

Connell, R. W., \& Messerschmidt, J. W. (2005). Hegemonic Masculinity Rethinking the Concept. Gender \& Society, 19(6), 829-859. doi:10.1177/0891243205278639

Connell, R. (2014). The sociology of gender in Southern perspective.Current Sociology, 62(4), 550-567. doi:10.1177/0011392114524510

Donaldson, M., Hibbins, R., Howson, R., \& Pease, B. (2009). Migrant men : critical studies of masculinities and the migration experience. New York: Routledge.

Eisenberg, Michael L. et al. (2009) Racial Differences in Vasectomy Utilization in the United States: Data From the National Survey of Family Growth. Urology 74: 1020-1024. Retrieved from: http://ill.lib.pdx.edu/PDF/381390.pdfp

Fernandez-Esquer, M. E., Diamond, P., \& Atkinson, J. (2010). Lazos que Atan: The Influence of Normative Gender Beliefs on Sexual Risk Behaviors of Latino Men and Women. Journal of Applied Social Psychology, 40(12), 2969-2994. doi:10.1111/j.1559-1816.2010.00689.x

Gutmann Matthew. (2004). Hombres carnales: Las políticas somáticas de la salud reproductiva masculina. Maguaré, (18). Web 21 Nov. 2014. Retrieved from: http://www.humanas.unal.edu.co/colantropos/documentos/maguare18.pdf

Gutmann, M. (2007). Fixing men : Sex, birth control, and AIDS in Mexico. Berkeley: University of California Press.

Inhorn, M. C. and Wentzell, E. A. (2011), Embodying emergent masculinities: Men engaging with reproductive and sexual health technologies in the Middle East and Mexico. American Ethnologist, 38: 801-815. doi: 10.1111/j.1548-1425.2011.01338.x 
Krogstad, J. M., \& Lopez, M. H. (n.d.). Hispanic Nativity Shift. Retrieved October 28, 2015, fromhttp://www.pewhispanic.org/2014/04/29/hispanic-nativity-shift/

Lu, A., \& Wong, Y. J. (2014). Stressful Experiences of Masculinity Among Young U.s.-Born and Immigrant Latino American Men. Culture, Society and Masculinities, 6(2), 111128. Retrieved fromhttp://search.proquest.com/docview/1673056154/abstract/69E1F8F14B964 19APQ/1?accountid=10226

Martínez Hernández, A. (2012). Masculinidades: su representación en la ficción televisiva. Derecho a comunicar, 4, 120-139. Retrieved from: http://132.248.9.34/hevila/Derechoacomunicar/2012/no4/7.pdf

Maternowska, M., Withers, M., \& Brindis, C. (2014). Gender, masculinity and migration: Mexican men and reproductive health in the Californian context. Culture, Health \& Sexuality, 16(8), 989-1002.

Montoya, R., Frazier, Lessie Jo, \& Hurtig, Janise. (2002). Gender's place : Feminist anthropologies of Latin America (1st ed.). New York: Palgrave Macmillan.

Nguyen, B.; Shih, G.; Turok, D. (2014). Putting the Man in Contraceptive Mandate. Association of Reproductive Health Professionals. Retrieved from https://www.arhp.org/publications-and-resources/contraception-journal/january2014

Ortner, S. B. (1989). Gender Hegemonies. Cultural Critique, (14), 35-80. Web. Retrieved from: http://dx.doi.org/10.2307/1354292

Penteado, L. G., Cabral, F., Diaz, M., Diaz, J., Ghiron, L., \& Simmons, R. (2001). Organizing a Public-Sector Vasectomy Program in Brazil.Studies in Family Planning, 32(4), 315328. Retrieved from: http://www.jstor.org/stable/2696319

Pile, J., \& Barone, M. (2009). Demographics of vasectomy--USA and international. The Urologic Clinics of North America, 36(3), 295-305. Retrieved from: http://www.sciencedirect.com/science/article/pii/S0094014309000470

Planned Parenthood Federation of America. (2014). Birth Control. Retrieved from: http://www.plannedparenthood.org/learn/birthcontrol/ 
Pomales, T. O. (2013). Men's Narratives of Vasectomy. Medical Anthropology Quarterly, 27(1), 23-42. Retrieved from: http://onlinelibrary.wiley.com.proxy.lib.pdx.edu/doi/10.1111/maq.12014/full

Ranji, U., Salganicoff,A., Stewart, A., Cox, M., Doamekpor, L. (2009) State Medicaid Coverage of Family Planning Services: Summary of State Survey Findings. The Kaiser Family Foundation. Retrieved from https://kaiserfamilyfoundation.files.wordpress.com/2013/01/8015.pdf

Reiter, R. (1975). Toward an anthropology of women. New York: Monthly Review Press.

Sable, M. R. \& Campbell, J. D. \& Schwarz, L. R. \& Brandt, J. \& Dannerbeck, A.(2006). Male Hispanic Immigrants Talk about Family Planning. Journal of Health Care for the Poor and Underserved 17(2), 386-399. The Johns Hopkins University Press. Retrieved from Project MUSE database:

https://muse.jhu.edu/login?auth=0\&type=summary\&url=/journals/journal_of_heal th_care_for_the_poor_and_underserved/v017/17.2sable.html.

Shih, G., Dubé, K., Sheinbein, M., Borrero, S., \& Dehlendorf, C. (2013). He’s a Real Man A Qualitative Study of the Social Context of Couples' Vasectomy Decisions Among a Racially Diverse Population. American Journal of Men's Health, 7(3), 206-213. http://doi.org/10.1177/1557988312465888

Torres, J. B. (1998). Masculinity and gender roles among Puerto Rican men: Machismo on the U.S. mainland. American Journal of Orthopsychiatry, 68(1), 16-26. http://doi.org/10.1037/h0080266

Vasquez del Aguila, E. (2014). Being a man in a transnational world : the masculinity and sexuality of migration. New York: Routledge.

Velasco Ortiz, M. (2005). Mixtec transnational identity. Tucson: University of Arizona Press.

Vernon, R. (1996). Operations Research on Promoting Vasectomy in Three Latin American Countries. International Family Planning Perspectives, 22(1), 26-31. Web. 20 Oct. 2014. Retrieved from: http://www.jstor.org.proxy.lib.pdx.edu/stable/2950799

Weis, L., Centrie, C., Valentin-Juarbe, J., \& Fine, M. (2002). Puerto Rican Men and the Struggle for Place in the United States An Exploration of Cultural Citizenship, Gender, and Violence. Men and Masculinities,4(3), 286-302. http://doi.org/10.1177/1097184X02004003004 